\title{
An Overall Furnace Model for the Silicomanganese Process
}

\author{
MANUEL SPARTA $\oplus^{1,3},{ }^{1,3}$ VETLE KJÆR RISINGGÅRD, ${ }^{1}$ \\ KRISTIAN ETIENNE EINARSRUD, ${ }^{2}$ and SVENN ANTON HALVORSEN ${ }^{1}$ \\ 1.-NORCE Norwegian Research Centre AS, Universitetsveien 19, 4630 Kristiansand S, Norway. \\ 2.-Department of Material Science and Engineering, Norwegian University of Science and \\ Technology, 7491 Trondheim, Norway. 3.—e-mail: masp@norceresearch.no
}

Controlling and optimizing smelting processes in submerged-arc furnaces are complicated by the limited amount of information available regarding the internal conditions. Computer models can help to bridge this knowledge gap. Due to the process complexity, computer models are commonly restricted to electrical conditions, thermal conditions, or chemical reactions, for instance. We have developed an overall model for a pilot-scale silicomanganese furnace that simultaneously considers electrical and thermal conditions, process chemistry, and flow of solid and liquid substances. To the best of our knowledge, this is the first comprehensive silicomanganese furnace model. The model has been compared to experimental data. Using information about the inner state of the furnace provided by the model, we are able to predict and explain an increase in temperature during over-coking as well as changes in the product compositions.

\section{INTRODUCTION}

Silicomanganese is produced by carbothermic reduction of manganese oxides and quartz in a submerged-arc furnace. ${ }^{1,2}$ Pilot-scale experiments have been used to understand aspects of the electrical operation, process chemistry, effect of different raw materials, and effects of trace elements. ${ }^{3-11}$ This article describes a comprehensive model for a pilot-scale silicomanganese furnace. Previous models have considered isolated aspects of the furnace, such as electrical conditions or the flow of raw materials. ${ }^{7,8,12}$ To the best of our knowledge, this is the first complete model that incorporates electrical and thermal conditions, process chemistry, flow of solid and liquid phases, and the production of gaseous substances. Independent efforts of a similar scope have previously been undertaken for silicon furnaces. ${ }^{13,14}$

Due to the intrinsic complexity of a submergedarc furnace, modeling efforts have considered several fundamentally different approaches. For instance, the flow of solid raw materials may be modeled as either discrete particles or a continuous fictitious fluid. ${ }^{15}$ Similarly, the flow of molten oxides has been considered in terms of both free-surface droplets and a continuous multiphase model. ${ }^{12}$ The present model considers flow of granular material and molten oxides in terms of fictitious fluids. The resulting flow fields determine the advection rates of the chemical species. Reactions among the species are considered sources and sinks in the advection equations in a manner similar to that in Ref. 16, but on a local rather than a global scale. The relative concentrations of the species determine properties such as the electrical conductivity and heat capacity of the effective medium. The inner workings of the model are considered in more detail in "Description of the Model" section.

Furnace operation is complicated by the limited amount of information available regarding the conditions inside the furnace hearth. An important asset of computer models is their ability to inform understanding by assigning a specific furnace condition to the external parameters available. Comprehensive furnace models, such as the one described in this article, could be used as point of departure for developing inverse metamodels that accomplish this task. ${ }^{17,18}$ 


\section{PILOT FURNACE}

The pilot furnace considered in this work has been described previously by several authors. ${ }^{3-11} \mathrm{~A}$ majority of published studies operate the pilot furnace using an alternating current. References 4 and 8 consder FeMn production, whereas most other studies produce SiMn, although alloy composition typically changes throughout the run from FeMn to SiMn.

The dimensions of the furnace are indicated in Fig. 1a. The furnace is insulated by an alumina refractory lining and a layer of silica sand, and it is equipped with one top and one bottom electrode. The electric system has a capacity of $440 \mathrm{kVA}$. The furnace is charged from the top with a uniform charge mix consisting of manganese ore, quartz, and

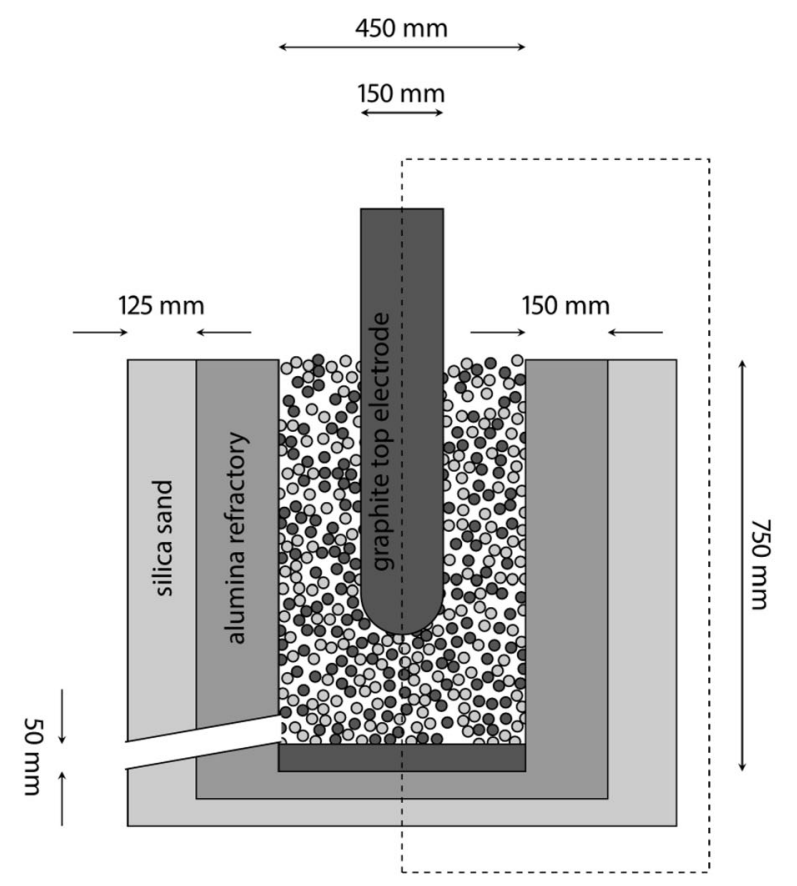

(a)

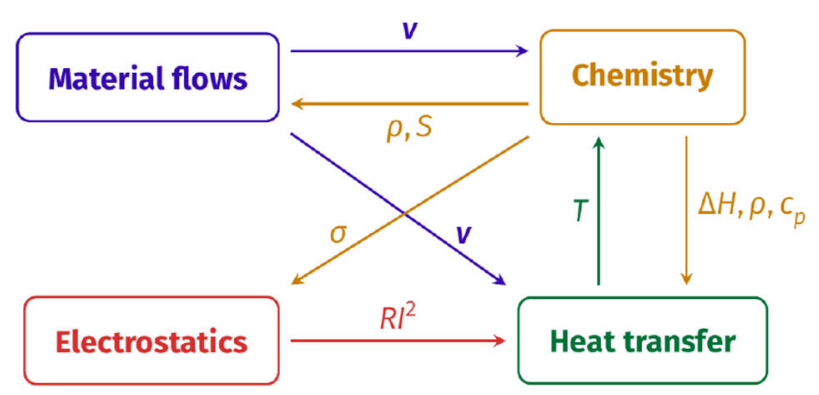

(b)

Fig. 1. (a) Cross-section of the pilot furnace. A dashed line marks the geometry of the two-dimensional axisymmetric model investigated. (b) Modules and interactions. The functionality of the model can be understood in terms of five modules: granular flow and liquid flow, chemistry, electrostatics, and heat transfer. coke. Electric current is supplied via the electrodes, and the resulting resistive heating gives rise to the high temperatures that allow melting of the ores and the carbothermic reduction of the metal oxides. Molten alloy and slag are tapped periodically.

\section{DESCRIPTION OF THE MODEL}

The model is implemented in COMSOL Multiphysics ${ }^{19}$ using the finite-element method. ${ }^{20}$ Ignoring the tap hole, the furnace geometry can be considered axisymmetric (Fig. 1a); to improve the computational efficiency, the model is implemented using COMSOL's two-dimensional axisymmetric interface. The functionality of the model can be understood in terms of five modules: granular flow and liquid flow (collectively referred to as material flows), chemistry, electrostatics, and heat transfer; see Fig. $1 b$.

\section{Chemistry}

For this model, we assume a simplified charge consisting of manganese and silicon oxides and pure carbon. Other oxides $\left(\mathrm{CaO}, \mathrm{Fe}_{\mathrm{x}} \mathrm{O}_{\mathrm{y}}, \mathrm{Al}_{2} \mathrm{O}_{3}\right.$, etc.) in the ores or added as fluxes to modify the physical and chemical properties of the slag are not accounted for in this implementation.

Manganese can exist in a number of different oxidation states. ${ }^{21}$ Consequently, manganese-containing minerals carry a corresponding number of different manganese oxides, including $\mathrm{MnO}_{2}$, $\mathrm{Mn}_{2} \mathrm{O}_{3}, \mathrm{Mn}_{3} \mathrm{O}_{4}$, and $\mathrm{MnO}$. In a ferromanganese (FeMn) smelting furnace, higher oxides of manganese are reduced to $\mathrm{MnO}$ in solid-state reactions in the prereduction zone at the top of the furnace by hot CO gas. ${ }^{1,2}$ In silicomanganese furnaces that are recycling slag from ferromanganese furnaces, only $20-30 \%$ of the $\mathrm{Mn}$ sources are ores. ${ }^{2}$ Reduction of higher manganese oxides will take place in a manner similar to the prereduction found in the FeMn process for this charge fraction. However, for the sake of simplicity, our model assumes that $\mathrm{MnO}$ is the only manganese oxide present. Thermodynamic considerations show that the reduction of $\mathrm{MnO}$ occurs by direct reduction of liquid $\mathrm{MnO}$ by solid carbon, ${ }^{2}$

$$
\mathrm{MnO}(\mathrm{l})+\mathrm{C}(\mathrm{s}) \rightarrow \mathrm{Mn}(\mathrm{l})+\mathrm{CO}(\mathrm{g}) .
$$

The only solid oxide of silicon relevant for silicomanganese production is $\mathrm{SiO}_{2}$, which is found in quartz and silicates. In the process, $\mathrm{SiO}_{2}$ dissolves into the slag phase. In keeping with the approach outlined for manganese above, the model only considers direct reduction of the dissolved $\mathrm{SiO}_{2}(\mathrm{l})$ with carbon ${ }^{2}$ as,

$$
\mathrm{SiO}_{2}(\mathrm{l})+2 \mathrm{C}(\mathrm{s}) \rightarrow \mathrm{Si}(\mathrm{l})+2 \mathrm{CO}(\mathrm{g}) .
$$

Simultaneous reduction of $\mathrm{MnO}$ and $\mathrm{SiO}_{2}$ gives rise to exchange of manganese and silicon metal and 
slag since the Gibbs free energy of formation of silicon is larger than that of manganese. ${ }^{2,22}$ Reduction of manganese oxide by silicon takes place by a combination of Reactions (1) and (2),

$$
\mathrm{Si}(\mathrm{l})+2 \mathrm{MnO}(\mathrm{l}) \rightarrow \mathrm{SiO}_{2}(\mathrm{l})+2 \mathrm{Mn}(\mathrm{l}) .
$$

In addition to Reactions (1) through (3), the model includes melting of $\mathrm{MnO}(\mathrm{s})$ and the dissolution of $\mathrm{SiO}_{2}(\mathrm{~s})$ into the slag,

$$
\mathrm{MnO}(\mathrm{s}) \rightarrow \mathrm{MnO}(\mathrm{l})
$$

and

$$
\mathrm{SiO}_{2}(\mathrm{~s}) \rightarrow \mathrm{SiO}_{2}(\mathrm{l})
$$

As a result, the model considers eight chemical species- $\mathrm{MnO}(\mathrm{s}), \mathrm{MnO}(\mathrm{l}), \mathrm{Mn}(\mathrm{l}), \mathrm{SiO}_{2}(\mathrm{~s}), \mathrm{SiO}_{2}(\mathrm{l})$, $\mathrm{Si}(\mathrm{l}), \mathrm{C}(\mathrm{s})$, and $\mathrm{CO}(\mathrm{g})$ - and five chemical reactions, Reactions (1) through (5).

In reality there are two liquid phases, alloy and slag, with $\mathrm{Mn}(\mathrm{l})$ and $\mathrm{Si}(\mathrm{l})$ in the alloy and $\mathrm{MnO}(\mathrm{l})$ and $\mathrm{SiO}_{2}(\mathrm{l})$ in the slag phase. However, as described in "Liquid Flow" section, we treat the percolation of all liquid species in the same way. Moreover, we keep track of each chemical specie except $\mathrm{CO}(\mathrm{g})$ using a separate advection-diffusion equation,

$$
\frac{\partial c_{k}}{\partial t}-\frac{\partial}{\partial x_{i}}\left(D \frac{\partial c_{k}}{\partial x_{i}}\right)+v_{i} \frac{\partial c_{k}}{\partial x_{i}}+c_{k} \frac{\partial v_{i}}{\partial x_{i}}=R_{k}
$$

Here, $c_{k}$ is the concentration of the chemical specie $k$ in $\mathrm{mol} / \mathrm{m}^{3}, v_{i}$ the velocity components of this specie, $x_{i}$ the position coordinates, $D$ the diffusion constant of specie $k$, and $R_{k}$ the local rate of consumption or generation of the specie by reaction $\mathrm{k}$. The advection velocities of the solid and liquid species are determined by the velocity fields of the granular ("Granular Flow" section) and liquid ("Liquid Flow" section) flow, respectively. The melting of $\mathrm{MnO}$ and dissolution of $\mathrm{SiO}_{2}$ into the slag is set to occur above a temperature of $1500^{\circ} \mathrm{C}$ and $1530^{\circ} \mathrm{C}$, respectively. ${ }^{23}$ The reduction reactions are assumed to be of first order and to follow Arrhenius law for the temperature dependence. We stress that, in agreement with the experimental observations, the reductions occur only for species in the liquid phase. The activation energies for the reduction of $\mathrm{MnO}$ and $\mathrm{SiO}_{2}$ are set to $200 \mathrm{~kJ} / \mathrm{mol}$ and $230 \mathrm{~kJ} / \mathrm{mol}$, in fair agreement with the available experimental data. ${ }^{24}$

\section{Granular Flow}

Granular flow is described in terms of a fictitious fluid using the dissipative Coulomb model ${ }^{25}$ which compares favorably with experiments for dense granular flows ${ }^{26}$ and is based on the Navier-Stokes equations for incompressible flow,

$$
\rho\left(\frac{\partial v_{i}}{\partial t}+v_{k} \frac{\partial v_{i}}{\partial x_{k}}\right)=-\frac{\partial p}{\partial x_{i}}+\frac{\partial}{\partial x_{k}}\left[\eta\left(\frac{\partial v_{i}}{\partial x_{k}}+\frac{\partial v_{k}}{\partial x_{i}}\right)\right]
$$

$$
\frac{\partial v_{i}}{\partial x_{i}}=0
$$

Here, $v_{i}$ are the velocity components, $x_{i}$ are the position coordinates, $p$ is the pressure, $\rho$ is the medium density, and $\eta$ is the medium viscosity. The local density of the effective medium is determined by the composition of the charge or coke bed as

$$
\rho=\sum_{i} \chi_{i} \rho_{i}
$$

where $\rho_{i}$ is the density of each component of the charge and $\chi_{i}$ is its volume fraction. The component densities are taken to be $5370 \mathrm{~kg} / \mathrm{m}^{3}(\mathrm{MnO}$; solid at room temperature $\left.{ }^{27}\right) 2500 \mathrm{~kg} / \mathrm{m}^{3}\left(\mathrm{SiO}_{2}\right.$; liquid at furnace temperatures ${ }^{28}$ ) and $2000 \mathrm{~kg} / \mathrm{m}^{3}$ (carbon; graphitized coke ${ }^{27}$ ). The viscosity is determined by the so-called granular temperature. ${ }^{29}$ The granular temperature is a measure of the deviations of individual particles from the average velocity of the medium. It can be calculated using an algebraic expression, ${ }^{30}$ and it depends on the particle size, inelasticity of collisions between particles, and local viscous stress.

In the lower part of the furnace, solids are transformed into liquids as the ore melts and the coke reacts increasing the local void fraction. The local void fraction is tracked and used to implement a "sink" term that drives the flow to replace the solids that have reacted. Further details can be found in the Supplementary Material.

\section{Liquid Flow}

As the oxides melt and react, the liquid oxides and metals flow down through the bottom of the charge and the coke bed. This process involves the formation of liquid droplets that subsequently trickle down through the granular layers. ${ }^{12,31}$

The present model takes a practical approach and avoids a detailed description of the free-surface flow following from droplet formation. ${ }^{12}$ When liquid species are present their flow is accounted for using the advection-diffusion equations in "Chemistry" section. The liquid velocity field is computed only once, at the start of the simulation. Further details can be found in the Supplemental Material.

\section{Gas Flow}

As the CO gas produced in the model does not react further (see "Chemistry" section), the model does not take gas flow explicitly into account. For 
the purpose of the material balance, the flux of $\mathrm{CO}$ escaping at the top of the furnace can be calculated as an integral over the gas-producing reactions in the charge.

The omission of gas flow implies that the model does not account for the gas-solid heat exchange and the heat transport from the core to the top of the furnace mediated by the gas. This means that the model overestimates the amount of heat that leaves the furnace with the gas. However, this deficiency is compensated by the fact that the charge that is added at the top of the furnace is pre-heated to about $300^{\circ} \mathrm{C}$. For the parameters that are used below, the amount of heat required for pre-heating the charge more or less balances the amount of heat that should have been exchanged between the gas and the solids.

\section{Electrostatics}

The model describes a furnace heated by Ohmic dissipation from a constant load of $150 \mathrm{~kW} .^{4-8}$ Most published studies for this pilot furnace use alternating currents, while we have assumed direct current. This approximation is valid for small furnaces, ${ }^{32,33}$ which is consistent with an experimental ratio of active to apparent power $(\cos \phi)$ close to one. ${ }^{7,8}$ For simplicity, the calculation of the electrical conditions is restricted to the electrodes and charge domains. The conductivity of the electrodes is set to $80 \mathrm{kS} / \mathrm{m},{ }^{27}$ whereas the conductivity of the charge depends on the local composition. Similarly to Eq. 8, the conductivity is computed as the sum of the conductivity of each component weighted by the volume fraction. The component conductivities are taken to be $400 \mathrm{~S} / \mathrm{m}$ (carbon $^{34}$ ) and $0.1 \mathrm{~S} / \mathrm{m}$ (charge; $\mathrm{MnO}-\mathrm{SiO}_{2}$ slag ${ }^{28}$ ) at the furnace temperature. Given the conductivity distribution $\sigma$ and the applied voltage, the electrostatic potential $V$ and the current density $\vec{J}$ are determined by solving the continuity equation,

$$
\frac{\partial J_{i}}{\partial x_{i}}=0, \quad J_{i}=\sigma E_{i}, \quad E_{i}=-\frac{\partial V}{\partial x_{i}},
$$

where $x_{i}$ are the position coordinates. The applied voltage is adjusted to maintain constant power. In the real system, such fine control is not possible, and large variations around the desired values have to be expected.

\section{Heat Transfer}

In addition to the Ohmic heating, the heat balance of the furnace consists of the reaction enthalpies as well as heat lost to the surroundings at the furnace surface. Heat generation, consumption, and transport are accounted for by solving the heat equation,

$$
\rho c_{p}\left(\frac{\partial T}{\partial t}+v_{i} \frac{\partial T}{\partial x_{i}}\right)-\frac{\partial}{\partial x_{i}}\left(k \frac{\partial T}{\partial x_{i}}\right)=Q .
$$

Here, $\rho$ is the local medium density, $c_{p}$ is its specific heat capacity, $k$ is its effective thermal conductivity, $T$ is its temperature, $v_{i}$ are the velocity components of the granular flow, $x_{i}$ are the position coordinates, and $Q$ is the local heat generation or consumption. Both the density and the heat capacity depend on the charge and coke bed compositions with the same formalism as in Eq. 8. The component heat capacities are taken to be $67 \mathrm{~J} / \mathrm{mol} \mathrm{K}$ $\left(\mathrm{MnO}^{35}\right), 86 \mathrm{~J} / \mathrm{mol} \mathrm{K}\left(\mathrm{SiO}_{2} ;\right.$ amorphous $\left.{ }^{36}\right)$, and $25 \mathrm{~J} / \mathrm{mol} \mathrm{K}$ (carbon; graphite ${ }^{37}$ ).

The thermal conductivity is taken to be independent of the charge composition, but considers the void fraction and particle size of the charge and takes special care of radiative heat transport in pores and voids. Our model is identical to the one derived by Ref. 38, except for a contribution from heat conduction through the particle contact points added in series with the radiative contribution. A similar model is discussed by Ref. 39. We use a particle thermal conductivity of $k_{1}=30 \mathrm{~W} / \mathrm{m} \mathrm{K}$ (anthracite ${ }^{40}$, a contact-point effective thermal conductivity of $k_{2}=2 \mathrm{~W} / \mathrm{mK}$, a particle diameter of $30 \mathrm{~mm}$, and an emissivity of 0.9 .

\section{Charging and Tapping}

The pilot furnace is charged in batches and is tapped periodically every $80 \mathrm{kWh}$ (about twice per hour). ${ }^{4-8}$ Conversely, the model simulates continuous tapping by removing liquid metal or slag that reaches the bottom electrode and continuous charging from the top that compensates for the downward solid movement.

Continuous charging is implemented by setting the concentration of the input materials as constant at the open boundary at the top of the furnace. For the study discussed here, the input concentrations of $\mathrm{MnO}, \mathrm{SiO}_{2}$ and carbon are fixed to $14.4 \mathrm{kmol} / \mathrm{m}^{3}$, $9.0 \mathrm{kmol} / \mathrm{m}^{3}$, and $22.5 \mathrm{kmol} / \mathrm{m}^{3}$, respectively. This corresponds to ca. $27.9 \mathrm{~kg}, 14.8 \mathrm{~kg}$, and $7.4 \mathrm{~kg}$ of $\mathrm{MnO}, \mathrm{SiO}_{2}$, and carbon in a $50-\mathrm{kg}$ batch.

Liquid species are set to percolate with an superficial flow velocity at the bottom of the charge of $10 \mathrm{~cm} / \mathrm{min}$ and are removed from the system when they reach the bottom electrode. Appropriate accumulators are set to record the instantaneous and cumulative compositions of the liquid phases extracted.

\section{SIMULATION}

\section{From Start to Stable Operation}

Experimental runs of the pilot furnace start with preloading a coke-rich zone on top of the bottom electrode and with a relatively long heating phase. ${ }^{3-11}$ Conversely, the simulations of the model furnace start with the furnace loaded with a homogeneous charge. The ca. $0.10 \mathrm{~m}^{3}$ of available volume is filled with $37.0 \mathrm{~kg}$ of carbon, $105.0 \mathrm{~kg}$ of $\mathrm{MnO}$, and $55.6 \mathrm{~kg}$ of $\mathrm{SiO}_{2}$, and the temperature is 
set to $800^{\circ}$ C. Full power $(150 \mathrm{~kW})$ is applied starting at $t=0 \mathrm{~h}$. The simulated furnace time equals $6 \mathrm{~h}$. This matches the production phase of the experimental pilot runs, which is between 4 and 6 h. $^{3-11}$ All the coupled physics are solved simultaneously, and the furnace evolves rapidly. The Ohmic heating leads to a rapid increase of the temperature of the charge near the tip of the electrode, and the solids begin to melt. Within $10 \mathrm{~min}$, liquid material reaches the outlet and is tapped continuously, as described above. In the top panel of Fig. 2, the rate of tapping for slag and alloy is shown for the duration of the simulation. In the initial phase, mostly slag is produced, but after an initial peak the slag production stabilizes at ca. $40 \mathrm{~kg} / \mathrm{h}$ and decreases slightly toward the end of the run. Conversely, the alloy production is low initially and increases to reach a plateau at $t=2 \mathrm{~h}$. Compared to experiments, Ref. 11 reports average tapping rates of about $35 \mathrm{~kg} / \mathrm{h}$ for alloy and $60 \mathrm{~kg} /$ $\mathrm{h}$ for slag. However, this slag contains about one third $\mathrm{CaO}$, an oxide that passes through the furnace without being reduced. Disregarding the $\mathrm{CaO}$ content of the slag brings the tapping rate in line with the model considered here.

The bottom panel of Fig. 2 shows the composition of the alloy and slag. The most notable result is the increase of the Si content in the alloy: In the initial phase it is around $10 \%$, but it increases and stabilizes at $17 \%$ after $1.5 \mathrm{~h}$. The composition of the slag sees a slightly higher amount of $\mathrm{MnO}$ in the initial phase and an even composition of about $50 \%$ $\mathrm{MnO}$ and $50 \% \quad \mathrm{SiO}_{2}$ toward the end of the
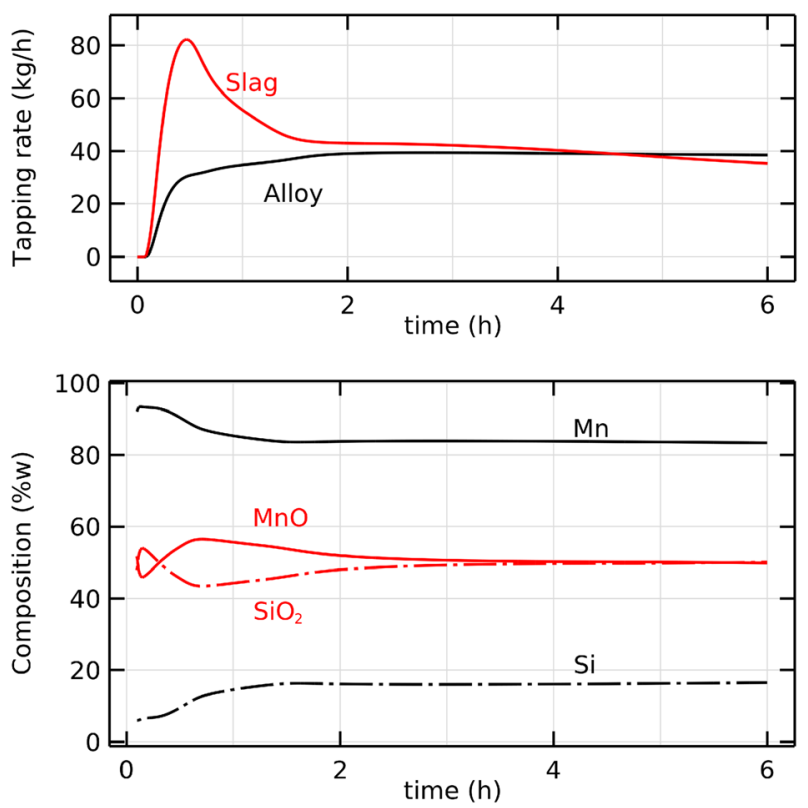

Fig. 2. Production throughout the $6 \mathrm{~h}$ run. Top panel: The tapping rate of slag and alloy $(\mathrm{kg} / \mathrm{h})$. Bottom panel: The composition of the slag and alloy $(\% w)$. simulation. Comparing again with Ref. 11, the silicon content of the alloy stabilizes at $10-20 \%$ in experimental runs of the pilot furnace and matches the simulations quite well, whereas the manganese content is higher in the simulations than in the experiments (decreasing from $40-50 \%$ to $16-30 \%$ throughout the run) because of the absence of iron in our model. Similarly, the increasing and decreasing trends of $\mathrm{SiO}_{2}$ and $\mathrm{MnO}$ in the slag agree with the trends in Ref. 11, but the weight fractions are off due to the lack of $\mathrm{CaO}, \mathrm{Al}_{3} \mathrm{O}_{3}, \mathrm{BaO}$, and $\mathrm{MgO}$ in the model.

The cumulative material balance of the furnace is shown in Table I. As expected, these numbers represent an average of the compositions that can be found in Fig. 2. In total, the silicon content in the alloy is $15.6 \%$, and $1.2 \mathrm{~kg}$ of slag is produced per $\mathrm{kg}$ of alloy.

In the top panel of Fig. 3, the specific energy consumption of the model-measured as $\mathrm{kWh}$ per $\mathrm{kg}$ of alloy produced-is shown as a function of time. In the initial phase, the specific energy consumption is about $6 \mathrm{kWh} / \mathrm{kg}$, but improves and reaches $3.9 \mathrm{kWh} / \mathrm{kg}$ around the $2 \mathrm{~h}$ mark. The explanation can be seen in the lower panel of the figure, where the major routes of the heat utilization are shown. During the first hour, the furnace is still warming up and heat is spent on increasing the temperature of the materials (internal heat balance). When the conditions for the endothermic reactions are met, the heat delivered to the furnace is increasingly consumed by the chemical reactions. After about $2 \mathrm{~h}$, the furnace stabilizes. During stable operation, the heat that is not consumed by the reactions is mainly lost by two different modes: either it is stored in the tapped materials (about $40 \mathrm{~kW}$ ) or transferred to the surroundings $(35 \mathrm{~kW})$. The latter term is computed as the heat lost via the external surfaces plus the heat removed by the off-gas minus the heat needed to preheat the charge.

The charge used in the initial load of the furnace is comparatively rich in carbon. This, and the high

Table I. Cumulative material balance

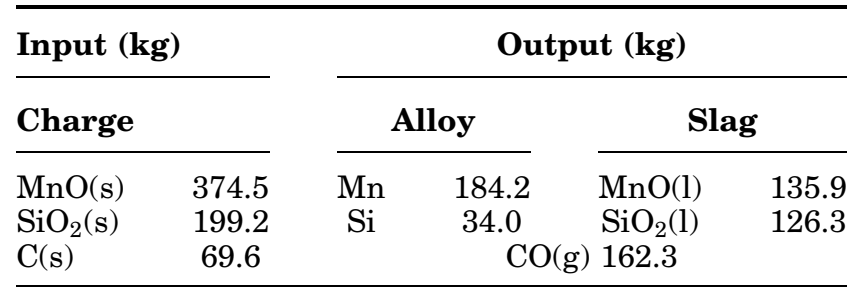

Total amounts of materials added to and extracted from the furnace $(\mathrm{kg})$. Material which is present in the furnace at the end of the simulation is removed from the input totals 

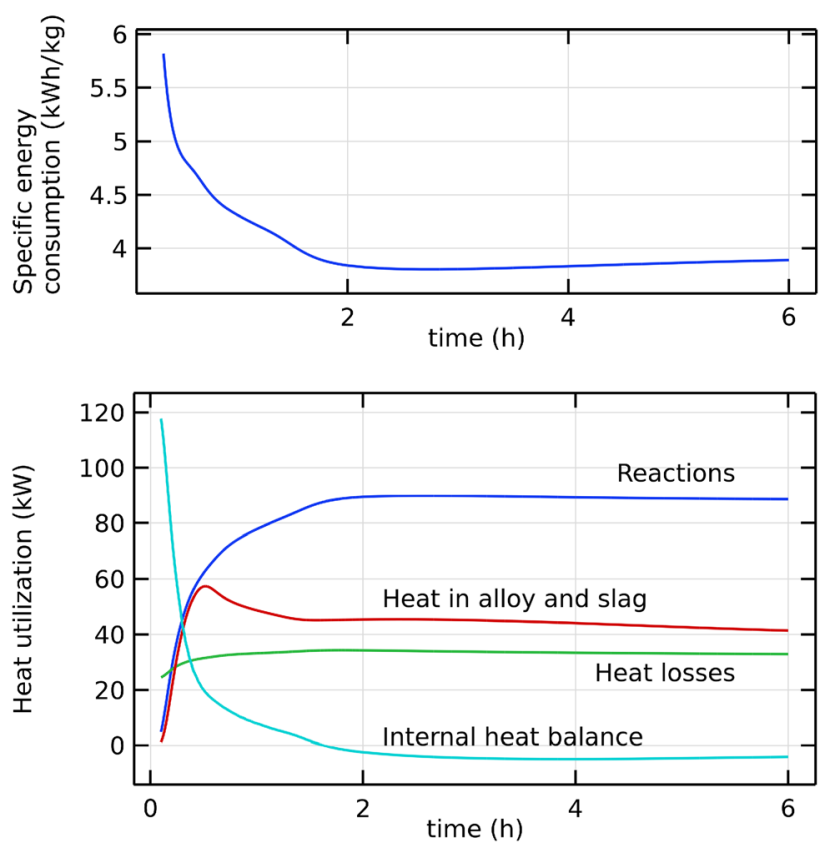

Fig. 3. Energy balance of the furnace. Top panel: Specific energy consumption measured in $\mathrm{kWh}$ per $\mathrm{kg}$ of alloy produced. Bottom panel: Major heat-consuming processes in the furnace $(\mathrm{kW})$.

production of slag in the initial phase, leads to the formation of a coke bed (carbon-enriched region) at the bottom of the furnace directly below the top electrode. An animation depicting the formation of the coke bed is available in the Supplementary Material. Within $1 \mathrm{~h}$ of the simulated furnace time, the coke bed reaches the bottom electrode, and it proceeds to expand into a truncated conic shape. After approximately $2 \mathrm{~h}$, all the initial charge has been replaced by fresh charge, with a composition of $2.5 \mathrm{~kg}$ of carbon, $11.4 \mathrm{~kg}$ of $\mathrm{MnO}$, and $6.1 \mathrm{~kg}$ of $\mathrm{SiO}_{2}$ for a $20 \mathrm{~kg}$ batch. Given the slag-to-alloy ratio for the simulated production, this charge corresponds to a slightly over-coked furnace, hence the slow increase in the size of the coke bed after about $2 \mathrm{~h}$ in the animation in the Supplementary Material.*

Figures 4 and 5 depict the status of the furnace at the end of the $6 \mathrm{~h}$ production run. The model allows access to information about the inside of the system that would be difficult to measure experimentally. For example, Fig. 4a shows the temperature distribution of the furnace interior. According to the simulation, the top of the charge and the external walls of the furnace stabilize around $300^{\circ} \mathrm{C}$. A large temperature gradient is established, and $50 \mathrm{~cm}$ below the surface - at the tip of the electrode- the temperature is $>1800^{\circ} \mathrm{C}$. The high temperature at the tip of the electrode is due to the concentration of

*Alternatively, the model can also be run such that the amount of carbon in the charge added to the furnace at the top matches the amount of carbon consumed in the furnace core, leading to a perfectly carbon-balanced furnace. the Ohmic power distribution close to this point as seen in Fig. 4b. The high currents and the relatively low conductivity in this zone result in a heat dissipation of $44 \mathrm{~kW}$ in about $6.5 \mathrm{dm}^{3}$ of charge, i.e., about one third of the power of the furnace is dissipated directly at the tip of the electrode. Figure 4c shows the heat balance in the furnace. Exothermic phenomena are dominating in regions colored in red (Ohmic heating and Mn-Si exchange), whereas blue regions are dominated by endothermic phenomena (melting and reduction of oxides).

The electrical conductivity and the current paths in the charge are shown in Fig. 4e, and the concentration of carbon is shown in Fig. $4 \mathrm{f}$. As can be seen by comparing the two panels, the coke bed gives rise to a local increase in the charge conductivity (ca. $260 \mathrm{~S} / \mathrm{m}$ ) compared to the $20 \mathrm{~S} / \mathrm{m}$ of the input charge. For comparison, the conductivity of the electrode is set to $80 \mathrm{kS} / \mathrm{m} .{ }^{27}$ It should be noted that the shape and extension of the carbon-rich zone are not imposed on the model (the initial conditions prescribe a homogeneous charge), but it is a result of the temperature distribution and the chemical reactions. The electric potential calculated by the simulation is shown in Fig. 4d. The voltage drop is $45 \mathrm{~V}$ and the current is $3.3 \mathrm{kA}$, giving a furnace resistance of $13.5 \mathrm{~m} \Omega$.

Material concentrations are also hard to measure experimentally during a furnace run. Figure $5 a, b$, and $\mathrm{c}$ shows the volume fractions of manganese oxide in the solid and melted form and the liquid Mn. Similarly, Fig. 5d, e, and f shows the volume fractions of silicon dioxide (solid and dissolved in the slag) and liquid Si.

\section{Over- and Under-Coking}

Having considered a slightly over-coked furnace, we now consider the changes that take place because of severe over- and under-coking. Starting from the state shown in Figs. 4 and 5, the furnace is run with a charge containing $140 \%$ of the original carbon content for $8 \mathrm{~h}$. Then, the carbon content of the charge is lowered to $60 \%$ of the original for an additional $8 \mathrm{~h}$.

Figure 6a shows the rate of the continuous tapping for the furnace in regimes of over- and undercoking. First, consider the time it takes for the change of the charge composition to affect the chemical reactions and the production of slag and alloy. Appreciable changes are only observed after $>1 \mathrm{~h}$. This is consistent with the fact that it takes $>1 \mathrm{~h}$ for the coke-rich charge to reach the reaction zone. However, when the coke-rich charge reaches the reaction zone, slag production decreases steadily for the remainder of the period of over-coking.

The addition of surplus carbon to the furnace results in an increase of the size of the coke bed. This is clearly seen in Fig. 7, which shows the concentration of carbon at $t=0 \mathrm{~h}, t=8 \mathrm{~h}$, and $t=16 \mathrm{~h}$, respectively. As reduction of liquid oxides 


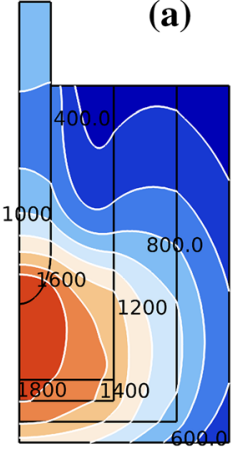

Temperature $\left({ }^{\circ} \mathrm{C}\right)$

(d)

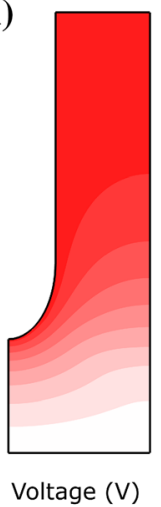

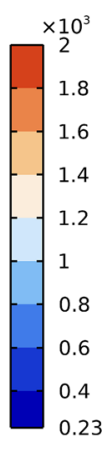

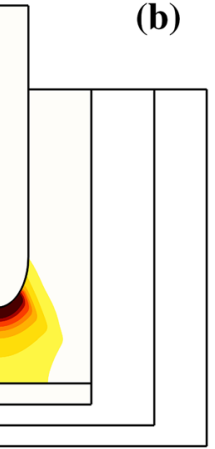

Ohmic heating $\left(\mathrm{MW} / \mathrm{m}^{3}\right)$

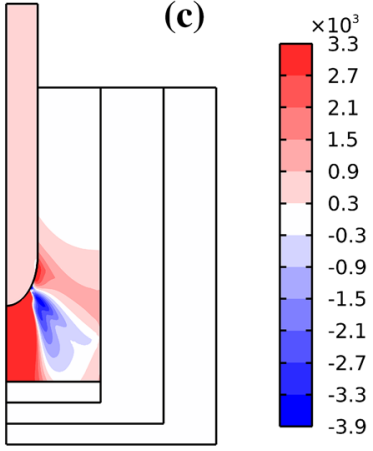

Power balance $(\mathrm{kW} / \mathrm{m} 3)$ (e)

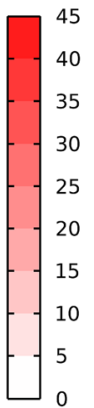

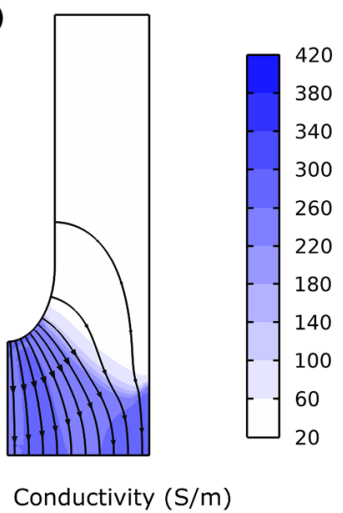

(f)

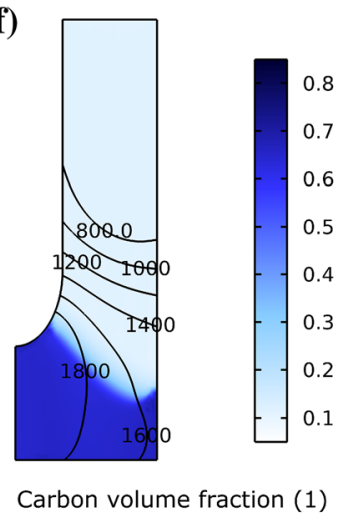

Fig. 4. Thermal and electrical conditions at $t=6 \mathrm{~h}$. (a) Furnace temperature profile $\left({ }^{\circ} \mathrm{C}\right)$. (b) Distribution of Ohmic heating $\left(\mathrm{MW} / \mathrm{m}^{3}\right)$. (c) Heat balance $\left(\mathrm{kW} / \mathrm{m}^{3}\right)$. (d) Electric potential in the charge $(\mathrm{V})$. (e) Electrical conductivity $(\mathrm{S} / \mathrm{m})$ and current paths. (f) Volume fraction of carbon (1).

to metal requires the simultaneous presence of oxides as well as carbon, the increase of the coke bed and the resulting displacement of the oxides move the production of metal higher in the furnace. This separates the endothermic alloy-producing reactions from the site of heat generation at the tip of the electrode. Since heat is no longer consumed at the electrode tip, the temperature of the coke bed increases, as shown in the isotherms of Fig. 7. We note that in industrial-size three-electrode furnaces over-coking leads to a decrease in the temperature of the furnace. The temperature increase we observe may indicate a unique feature of the pilot furnace-which has only a single electrode-or expose a shortcoming of the model. Turning to the energy balance, the heat required for this temperature increase is made available by the reduction in the amount of latent heat required for melting oxides (slag production decreases).
The model predicts that the reduction in slag production and the growth of the coke bed in the over-coked regime are accompanied by an increase in the amount of silicon in the alloy and a reduction in the amount of $\mathrm{MnO}$ in the slag (Fig. 6b). The reduction in the amount of $\mathrm{MnO}$ in the slag is likely due to the $\mathrm{Mn}-\mathrm{Si}$ exchange in Reaction (3). The positive correlation between the furnace temperature and the $\mathrm{Si}$ content in the alloy is well documented. ${ }^{3,4,9,11}$

At $t=8 \mathrm{~h}$ the amount of carbon is reduced and the furnace charge is under-coked for the remainder of the production run. We observe that it takes $1 \mathrm{~h}$ $40 \mathrm{~min}$ for the furnace to react to the under-coking. Once the furnace has started to consume the coke bed, there is a rapid increase in the slag production, a decrease in the amount of silicon in the alloy, and an increase in the amount of $\mathrm{MnO}$ in the slag (Fig. 6). As Fig. 7 shows, $8 \mathrm{~h}$ of under-coking results 
(a)

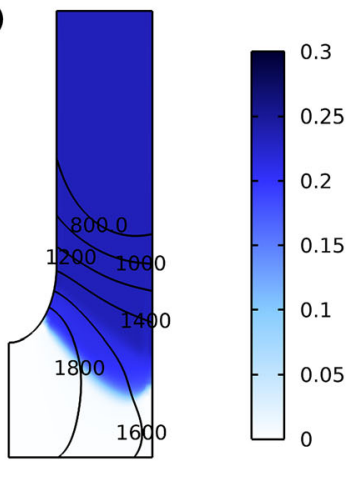

$\mathrm{MnO}(\mathrm{s})$ volume fraction (1) (b)

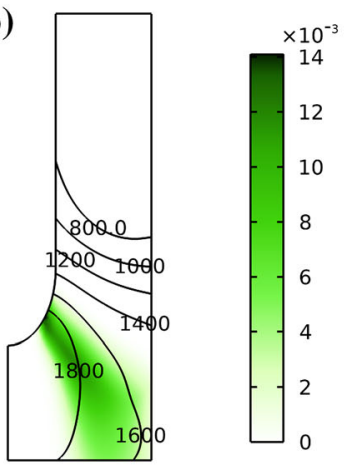

$\mathrm{MnO}(\mathrm{I})$ volume fraction (1) (c)

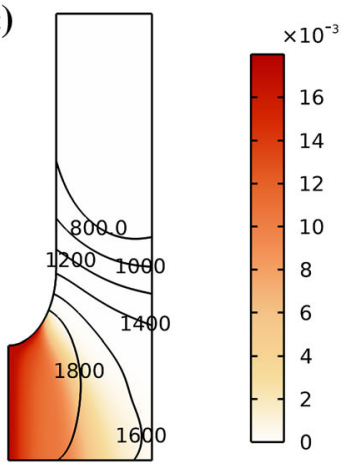

$\mathrm{Mn}(\mathrm{I})$ volume fraction (1) (d)

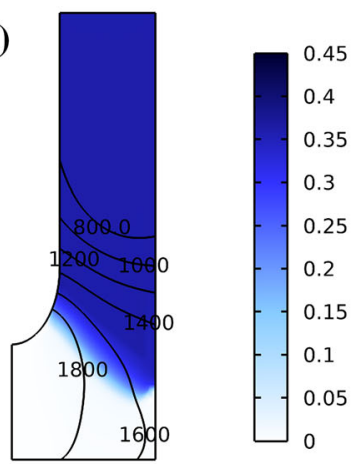

$\mathrm{SiO}_{2}(\mathrm{~s})$ volume fraction (1) (e)

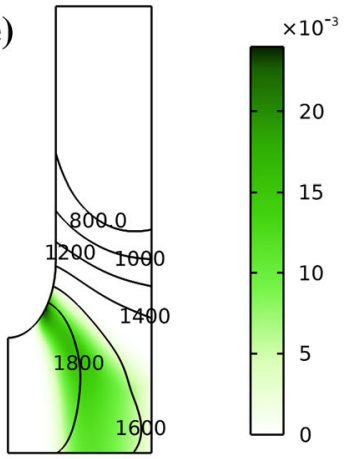

$\mathrm{SiO}_{2}(\mathrm{I})$ volume fraction (1) (f)

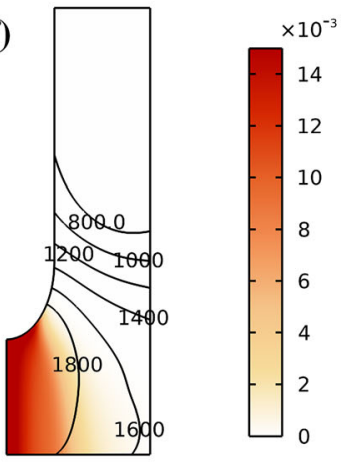

$\mathrm{Si}(\mathrm{I})$ volume fraction (1)

Fig. 5. Volume fractions of the different chemical species in the charge and temperature isotherms $\left({ }^{\circ} \mathrm{C}\right)$ at $t=6 \mathrm{~h}$. (a) $\mathrm{MnO}$ solid, (b) $\mathrm{MnO}$ liquid, and (c) Mn liquid. (d) $\mathrm{SiO}_{2}$ solid, (e) $\mathrm{SiO}_{2}$ liquid and (f) $\mathrm{Si}$ liquid.
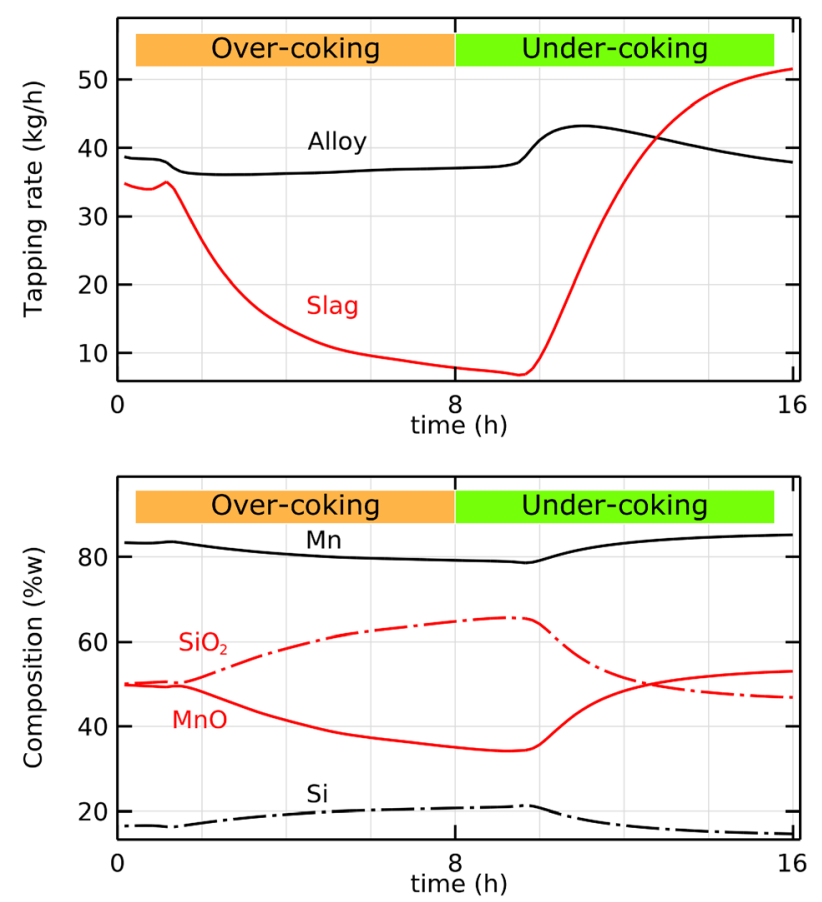

Fig. 6. Production throughout the $16 \mathrm{~h}$ production run. Top panel: The tapping rate of slag and alloy $(\mathrm{kg} / \mathrm{h})$. Bottom panel: The composition of slag and alloy (\%w). in a severe reduction of the coke bed and a corresponding reduction of the temperature of the lower part of the furnace.

\section{SUMMARY}

We have developed an overall model for a pilotscale silicomanganese furnace. The model considers the material flows, process chemistry, and electrical and thermal conditions of the furnace. Key process parameters predicted by the model-such as slag and alloy production rates, slag-to-alloy and siliconto-manganese ratios, and the furnace efficiency-are in agreement with values measured in experiments. ${ }^{11}$ The model also provides access to information that is not available experimentally, such as the internal temperature distribution of the furnace or the concentrations of the different chemical species inside the furnace during the production run. Using the values of these variables, we are able to predict and explain an increase in the temperature of the furnace during over-coking as well as changes in the product compositions.

\section{ACKNOWLEDGEMENTS}


(a)

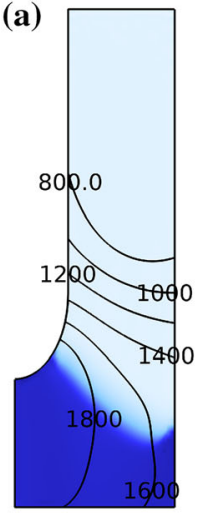

$\mathrm{t}=0(\mathrm{~h})$ (b)
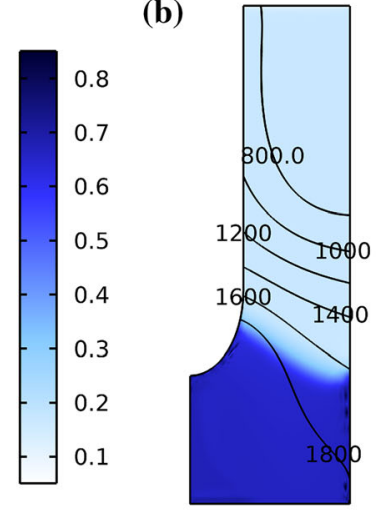

$\mathrm{t}=8(\mathrm{~h})$ (c)
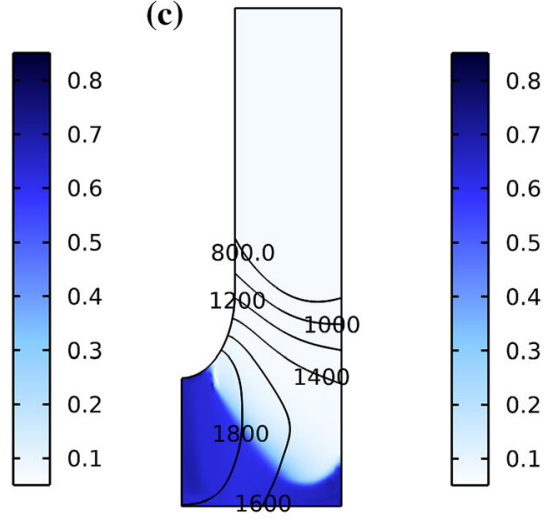

$\mathrm{t}=16(\mathrm{~h})$

Fig. 7. Volume fraction of carbon in the charge and temperature isotherms $\left({ }^{\circ} \mathrm{C}\right)$ during over- and under-coking. (a) Initial concentration at $t=0 \mathrm{~h}$. (b) Concentration after $8 \mathrm{~h}$ of over-coking. (c) Concentration after 8 additional hours of of under-coking.

This work is partly funded by SFI Metal Production (a Norwegian Centre for Research-based Innovation, project number 237738). The authors gratefully acknowledge the financial support from the Research Council of Norway and the partners of SFI Metal Production.

\section{FUNDING}

Open access funding provided by NORCE Norwegian Research Centre AS.

\section{CONFLICT OF INTEREST}

The authors declare that they have no conflict of interest.

\section{OPEN ACCESS}

This article is licensed under a Creative Commons Attribution 4.0 International License, which permits use, sharing, adaptation, distribution and reproduction in any medium or format, as long as you give appropriate credit to the original author(s) and the source, provide a link to the Creative Commons licence, and indicate if changes were made. The images or other third party material in this article are included in the article's Creative Commons licence, unless indicated otherwise in a credit line to the material. If material is not included in the article's Creative Commons licence and your intended use is not permitted by statutory regulation or exceeds the permitted use, you will need to obtain permission directly from the copyright holder. To view a copy of this licence, visit $h$ ttp://creativecommons.org/licenses/by/4.0/.

\section{SUPPLEMENTARY INFORMATION}

The online version supplementary material available at https://doi.org/10.1007/s11837-021-04791-y.

\section{REFERENCES}

1. S.E. Olsen and M. Tangstad, in Proceedings of the Tenth International Ferroalloys Congress, INFACON $X$ (Cape Town, South Africa, 2004), p. 231.

2. S.E. Olsen, M. Tangstad, and T. Lindstad, Production of Manganese Ferroalloys (Tapir Akademisk Forlag, 2007).

3. M. Tangstad, B. Heiland, S.E. Olsen, and R. Tronstad, in Proceedings of the Ninth International Ferroalloys Congress, INFACON IX (Quebec City, Canada, 2001), p. 401.

4. M. Tangstad, E. Ringdalen, E. Manilla, and D. Davila, JOM 69, 358 (2017). https://doi.org/10.1007/s11837-016-2216-3.

5. B. Monsen, M. Tangstad, and H. Midtgaard, in Proceedings of the Tenth International Ferroalloys Congress, INFACON $X$ (Cape Town, South Africa, 2004), p. 392.

6. B. Monsen, M. Tangstad, I. Solheim, M. Syvertsen, R. Ishak, and H. Midtgaard, in Proceedings of the Eleventh International Ferroalloys Congress, INFACON XI (New Delhi, India, 2007), p. 297.

7. P.A. Eidem, M. Tangstad, and J.A. Bakken, Can. Metall. Q. 48, 355 (2009). https://doi.org/10.1179/cmq.2009.48.4.355.

8. P.A. Eidem, M. Tangstad, J.A. Bakken, and R. Ishak, in Proceedings of the Twelvth International Ferroalloys Congress, INFACON XII (Helsinki, Finland, 2010), p. 349.

9. E. Ringdalen and M. Tangstad, in Proceedings of the Thirteenth International Ferroalloys Congress, INFACON XIII (Almaty, Kazakhstan, 2013), p. 195.

10. Y. Ma, E. Moosavi-Khoonsari, I.T. Kero, and G.M. Tranell, Metall. Materi. Trans. B 49, 2444 (2018). https://doi.org/10. 1007/s11663-018-1358-9.

11. E. Ringdalen and I. Solheim, in Proceedings of the Fifteenth International Ferroalloys Congress, INFACON XV (South African Institute of Mining and Metallurgy, Cape Town, South Africa, 2018).

12. S. Letout, A.P. Ratvik, M. Tangstad, S.T. Johansen, and J.E. Olsen, in Progress in Applied CFD, SINTEF Proceedings (SINTEF Academic Press, 2017), p. 599.

13. B. Andresen and J.K. Tuset, in Proceedings of the Seventh International Ferroalloys Congress, INFACON VII (Trondheim, Norway, 1995), p. 535.

14. D. Darmana, J.E. Olsen, K. Tang, and E. Ringdalen, in Ninth International Conference on CFD in the Minerals and Process Industries (CSIRO, Melbourne, Australia, 2012).

15. M. Sparta and S.A. Halvorsen, in CFD2017: Proceedings of the 12th International Conference on Computational Fluid Dynamics in the Oil \& Gas, Metallurgical and Process Industries (SINTEF Academic Press, Trondheim, Norway, 2017), p. 593.

16. B.M. Sloman, C.P. Please, R.A. Van Gorder, A.M. Valderhaug, R.G. Birkeland, and H. Wegge, Metall. Mater. Trans. 
B 48, 2664 (2017). https://doi.org/10.1007/s11663-017-10523 .

17. K. Stråbø, Metamodelling and inverse metamodelling electrical conditions in ferromanganese furnaces. Master's thesis, Norwegian University of Science and Technology, Trondheim, Norway (2020).

18. M. Sparta, D. Varagnolo, K. Stråbø, S..A. Halvorsen, E..V. Herland, and H. Martens, Metall. Materi. Trans. B 52(3), 1267 (2021). https://doi.org/10.1007/s11663-021-02089-7.

19. COMSOL Inc. COMSOL Multiphysics (2020). https://www.c omsol.com/.

20. K.J. Bathe, Finite Element Procedures, 2nd edn. (PrenticeHall, Hoboken, 2014).

21. S.S. Zumdahl, Chemical Principles (Brooks/Cole, 2010).

22. R.J. Pomfret and P. Grieveson, Can. Metall. Q. 22, 287 (1983). https://doi.org/10.1179/cmq.1983.22.3.287.

23. P.P. Kim, Reduction rates of SiMn slags from various raw materials. PhD Thesis, Norwegian University of Science and Technology, Trondheim, Norway (2018).

24. V. Canaguier and M. Tangstad, Metall. Materi. Trans. B 51(3), 953 (2020). https://doi.org/10.1007/s11663-020-018013.

25. R. Artoni, A. Santomaso, and P. Canu, AIP Conf. Proc. 1027, 941 (2008). https://doi.org/10.1063/1.2964902.

26. A. Zugliano, R. Artoni, A. Santomaso, A. Primavera, and M. Pavličević, in Proceedings of the COMSOL Conference (Hannover, Germany, 2008).

27. W.M. Haynes, D.R. Lide and T.J. Bruno, CRC Handbook of Chemistry and Physics, 97th edn. (CRC Press, Boca Raton, 2017).

28. M. Allibert, H. Gaye, J. Geiseler, D. Janke, B.J. Keene, D. Kirner, M. Kowalski, J. Lehmann, K.C. Mills, D. Neuschütz, R. Parra, C. Saint-Jours, P.J. Spencer, M. Susa, M. Tmar, and E. Woermann, Slag Atlas, 2nd edn. (Verlag Stahleisen $\mathrm{GmbH}$, Düsseldorf, 1995).

29. I. Goldhirsch, Powder Technol. 182, 130 (2008). https://doi. org/10.1016/j. powtec.2007.12.002.
30. M. Syamlal, W. Rogers, and T.J. O'Brien, MFIX documentation: Theory guide. DOE Technical Report DOE/METC94/1004 (1993). https://doi.org/10.2172/10145548.

31. W.M. Husslage, T. Bakker, A.G.S. Steeghs, M.A. Reuter, and R.H. Heerema, Metall. Materi. Trans. B 36, 765 (2005). https://doi.org/10.1007/s11663-005-0080-6.

32. S.A. Halvorsen, H.A.H. Olsen, and M. Fromreide, IFACPapersOnLine 49(20), 167 (2016). https://doi.org/10.1016/j. ifacol.2016.10.115.

33. M. Fromreide, D. Gómez, S.A. Halvorsen, E.V. Herland, andd P. Salgado, Appl. Math. Model. S0307904X21002377 (2021). https://doi.org/10.1016/j.apm.2021.04.034.

34. G.R. Surup, T.A. Pedersen, A. Chaldien, J.P. Beukes, and M. Tangstad, Processes 8(8), 933 (2020). https://doi.org/10. 3390/pr8080933.

35. Chemistry Software. HSC Chem. 9 (2016). http://www.che mistry-software.com/.

36. P. Richet, Y. Bottinga, L. Denielou, J. Petitet, and C. Tequi, Geochim. Cosmochim. Acta 46(12), 2639 (1982). https://doi. org/10.1016/0016-7037(82)90383-0.

37. M.W. Chase (ed.), NIST-JANAF Thermochemical Tables, 4th edn. (American Chemical Society; American Institute of Physics; National Institute of Standards and Technology, 1998).

38. W. Schotte, AIChE J. 6, 63 (1960). https://doi.org/10.1002/a ic. 690060113

39. A.L. Loeb, J. Am. Ceram. Soc. 37, 96 (1954). https://doi.org/ 10.1111/j.1551-2916.1954.tb20107.x.

40. K.B. Kiradjiev, S.A. Halvorsen, R.A. Van Gorder, S.D. Howison, Int. J. Therm. Sci. 145, 106009 (2019). https://doi. org/10.1016/j.jithermalsci.2019.106009.

Publisher's Note Springer Nature remains neutral with regard to jurisdictional claims in published maps and institutional affiliations. 